\title{
Effect of Natural Substances as Antioxidants and as Corrosion Inhibitors of Carbon Steel on Soybean Biodiesel
}

\author{
Carlos Alberto Caldas de Souza ${ }^{a}$, Marilena Meira ${ }^{b}$, Lucas Oliveira de Assis ${ }^{c}$, \\ Rafael Santos Barbosad ${ }^{d}$, Saionara Luna ${ }^{* *}$ (1) \\ ${ }^{a}$ Universidade Federal da Bahia, Escola Politecnica, Departamento de Ciência e Tecnologia de \\ Materiais, Rua Aristides Novis 2, Federação, CEP: 40240-550, Salvador, BA, Brasil. \\ ${ }^{b}$ Instituto Federal de Educação, Ciência e Tecnologia da Bahia, Departamento de Química, Via \\ universitária, s/n, Pitanguinhas, CEP: 43700-000Simões Filho, BA, Brasil. \\ ${ }^{c}$ Universidade Federal da Bahia, Escola Politecnica, Departamento de Engenharia Mecânica, Rua \\ Aristides Novis 2, Federação, CEP: 40240-550, Salvador, BA, Brasil. \\ ${ }^{d}$ Universidade Federal da Bahia, Escola Politecnica, Departamento de Engenharia Industrial, Rua \\ Aristides Novis 2, Federação, CEP: 40240-550, Salvador, BA, Brasil. \\ ${ }^{e}$ Universidade Federal da Bahia, Escola Politecnica, Departamento de Engenharia Química, Rua \\ Aristides Novis 2, Federação, CEP: 40240-550, Salvador, BA, Brasil.
}

Received: May 30, 2020; Revised: March 29, 2021; Accepted: June 24, 2021

The use of natural additives in biodiesel has been investigated, however, there is limited information in the literature in relation to their influence on corrosion resistance and oxidative stability. This work aims to investigate the oxidative stability of biodiesel and the corrosion resistance of carbon steel (AISI 1020) in contact with soybean biodiesel solutions (B100) in the presence and absence of natural additives such as: rosmarinic acid, curcumin, gingerol, eugenol, thymol and quercetin. Corrosion and microscopy tests were used to assess corrosion resistance. The Rancimat technique was used to study oxidative stability. The results obtained indicate that curcumin was the best additive in relation to oxidative stability, while rosmarinic acid showed better performance in inhibiting corrosion. The effect of these substances is related to the presence of phenolic compounds or the existence of oxygen in its molecular structure.

Keywords: Biodiesel, corrosion, oxidative stability, natural additives.

\section{Introduction}

Biodiesel is obtained the transesterification reaction of vegetable oils or animal lipids with metanol or ethanol, in general, in the presence of basic catalyst, such as $\mathrm{KOH}$ and $\mathrm{NaOH}$. Through this reaction, the feedstock is transformed into fatty acid methyl or ethyl esters, which constitutes biodiesel ${ }^{1}$. Soybean oil is one of the main raw materials used to obtain biodiesel and in Brazil about $90 \%$ of biodiesel is obtained from soybean oil ${ }^{1}$. In the process of obtaining biodiesel from soybean oil, a conversion of $97.5 \%$ of oil into methyl esters was obtained ${ }^{2}$. In this process, a loss of $10 \%$ was estimated, which tends to be reduced with the recovery of ethanol and the commercialization of glycerol.

Soybean biodiesel has the advantage of being environmentally friendly and is obtained from a high yielding oilseed. However, soybean biodiesel oxidizes very easily because it contains in its composition fatty acids such as linolenic, palmitic, oleic, and linoleic acids. These acids are unsaturated and are therefore easily oxidized, forming oil degradation compounds such as free acids, alcohols, and peroxides ${ }^{3,4}$.

*email: saionaraluna@gmail.com
The low oxidative stability and corrosion caused by biodiesel in automotive components can cause significant damage to the vehicle, making its use impractical. Biodiesel degradation due to its oxidation occurs over time during storage and oxidation is accelerated by exposure to air (presence of water and oxygen), environmental conditions (heat and light), attack by microorganisms and metals from automotive materials and containers ${ }^{5,6}$.

Biodiesel oxidation occurs through the process of removal of oxygen and / or hydrogen from the carbon chain, producing hydroperoxide, peroxides and carboxylic acids ${ }^{7-9}$. Oxidized biodiesel has higher viscosity because of the occurrence of a polymerization reaction involving double bonds, which in later stages lead to the formation of hydroperoxides. These can produce insoluble materials, such as gum and sediments that can obstruct the fuel filters ${ }^{10}$.

Increased viscosity leads to weak fuel atomization and consequently biodiesel enters the crankcase which can cause engine failure ${ }^{11}$. In the oxidized state it has been found ${ }^{12}$ that biodiesel increases the emission of organic substances harmful to human health such as acrolein, formaldehyde, and acetaldehyde, in addition to increasing NOx emissions ${ }^{13}$. The oxidation of the biodiesel can also cause corrosion of components of the fuel injection system due to the elevation 
of acidity and the presence of hydroperoxides resulting from oxidation ${ }^{10}$.

It is well-known that biodiesel is more corrosive than petroleum diesel, and that biodiesel causes corrosion of metallic components of engine fuel systems ${ }^{6}$. The higher corrosiveness of biodiesel is attributed mainly to the fact that biodiesel absorbs a greater amount of water from the atmosphere and has a higher electrical conductivity than petroleum diesel. The higher electrical conductivity favors the oxide-reduction reaction, thus making the corrosive process more intense. Biodiesel is hygroscopic and after long storage this can hydrolyze the ester bond giving rise to the formation of free fatty acids (FFA) that have corrosive characteristics $^{14}$.

With the addition of antioxidants to biodiesel it is possible to increase its oxidative stability and reduce its corrosiveness. Antioxidant additives do not completely stop oxidation, but significantly inhibit this process. This effect is attributed to the donation of hydrogen atoms or electrons from the antioxidant to the free radical (mainly peroxyl radical) thus neutralizing the oxidation reaction ${ }^{15}$. The release of $\mathrm{H}$ atoms is generally from the $\mathrm{OH}$ and / or $\mathrm{NH}$ groups present in the additive ${ }^{15,16}$.

Synthetic phenolic additives, such as, pyrogallol (PY), tertbutylhydroquinone (TBHQ), butylated hydroxytoluene (BHT), and propylgallate (PG) have been used as antioxidants in biodiesel and have shown a satisfactory effect ${ }^{17}$. However, artificial antioxidants are expensive and are generally toxic, non-biodegradable, and obtained from non-renewable raw materials. The use of natural antioxidant in biodiesel is therefore interesting. Nevertheless, little attention has been paid to the use of natural antioxidants in biodiesel ${ }^{18}$ until now. This is because is recent the concern to use non-polluting and biodegradable products obtained through renewable raw materials, as occurs with natural antioxidants. Research is necessary to evaluate the use of natural additives and test their effectiveness.

One of the most promising natural additives to be used as an antioxidant in biodiesel is turmeric extract which is a have a phenolic compound. It has been found ${ }^{19}$ that the addition of curcumin raises the oxidation induction period of soybean biodiesel by up to $83 \%$.

Carbon steel is the most used material in the manufacture of equipment and pipes such as high pressure line, feed tank, inlet and exhaust valve ${ }^{5}$ for biodiesel handling. Corrosion of carbon steel does not occur in pure biodiesel, however, the presence of sulfur molecules, acid compounds or water can cause chemical attack ${ }^{20}$. $\mathrm{H}_{2} \mathrm{CO}_{3}$ formed from the adsorption of $\mathrm{CO}_{2}, \mathrm{O}_{2}$, and $\mathrm{H}_{2} \mathrm{O}$ in biodiesel acts as a corrosive on steel ${ }^{21}$.

Regarding the effect of the presence of water on the corrosion of carbon steel in biodiesel, it has also been suggested $^{22}$ that water droplets in contact with the steel surface cause the presence of a corrosion cell by differential aeration. According to this mechanism, the anodic reactions occurs on the steel surface in contact with the central part of the water droplet, while the cathodic reaction occurs at the water-biodiesel interface due to the higher concentration of oxygen in that region.

In contact with biodiesel, the corrosion of carbon steel is related to the oxidation reaction of $\mathrm{Fe}$ to $\mathrm{Fe}^{2+}$ in the anode and in the cathode to the reaction of reducing oxygen in the presence of water. As a result of the reaction of Fe ions with $\mathrm{O}_{2}, \mathrm{CO}_{2}$, and $\mathrm{H}_{2} \mathrm{O}$, corrosion products are formed based on oxides, hydroxides and carbonates of $\mathrm{Fe}^{23,24}$. While oxides and hydroxides are present in petroleum diesel, the presence of organic compounds $\mathrm{FeCO}_{3}$ and $\mathrm{Fe}_{2} \mathrm{O}_{2} \mathrm{CO}_{3}$ also occurs in biodiesel, formed from the reaction between unsaturated fatty acids with the steel surface ${ }^{23}$. Chemical reactions for the formation of $\mathrm{FeCO}_{3}$ are presented in Equations 1 and $2^{25}$.

$R C O O R 1 \rightarrow R C O O *+R 1 *$

$2 \mathrm{RCOO}^{*}+\mathrm{Fe} \rightarrow \mathrm{FeCO}_{3}+\mathrm{R}-\mathrm{R}+\mathrm{CO}$

It has been proposed that the formation of $\mathrm{Fe}_{2} \mathrm{O}_{2} \mathrm{CO}_{3}$ occurs through the chemical reaction between $\mathrm{H}_{2} \mathrm{CO}_{3}$ and $\mathrm{FeO}(\mathrm{OH})$, which is produced through the redox reaction between $\mathrm{Fe}$, $\mathrm{O}_{2}$, and $\mathrm{H}_{2} \mathrm{O}_{2}$. With the formation of corrosion products, mainly iron rust $\left(\mathrm{Fe}(\mathrm{OH})_{2}\right)$, the anode reaction is partially blocked, however, the residual alkali in biodiesel interact with corrosion products which results in the deterioration of the quality of the biodiesel ${ }^{22}$.

The corrosion inhibition mechanism of carbon steel in biodiesel is related to the addition of corrosion inhibitors in the biodiesel. Corrosion inhibiting additives do not totally inhibit the corrosion caused by the biodiesel to the metal components of the engine, but they reduce corrosion by increasing the lifespan of the metal components ${ }^{26}$. This effect of the additives is attributed mainly to the formation of adsorbed monolayer films at the metal-solution interface which, prevents further interaction between the metal and the biodiese ${ }^{27}$ and also due to the possible reaction between the additive and the oxidation product, with the consequent reduction of the corrosive characteristic of the biodiesel.

The additives that act as corrosion inhibitors in biodiesel are generally organic compounds containing heterocyclic compounds, hydroxyl group, nitrogen, and oxygen atoms, whose free electrons form a bond with the surface of the metal. In the protection against the corrosion of carbon steel in biodiesel in general additives containing hydroxyl group are used, such as butylated hydroxytoluene (BHT), tert-butylamine (TBA), tert-butylhydroquinone (TBHQ), pyrogallol (PY) and propyl gallate $[\mathrm{TG}]^{27,28}$.

TBA is one of the most efficient corrosion inhibitors with an inhibition efficiency of about $86.5 \%$ for carbon steel and iron casting using $250 \mathrm{ppm}$ TBA in palm biodiese ${ }^{27}$. This effect of TBA is attributed to the presence of the amine group in its structure which, enables the formation of a protective film against corrosion. The presence of the $\mathrm{N}$ atoms in the TBA form a bond with the metal surface, thus allowing the formation of a $\mathrm{Fe}$ nitrate hydrate protective layer.

It has been found that the addition of BHT to a $20 \%$ biodiesel-diesel blend results in an inhibition of the corrosion of carbon steel of about $95 \%{ }^{29}$. The effect of BHT is attributed to the presence of a lone pair of electrons of the $\mathrm{OH}$ group through which the additive molecules is adsorbed on the metal surface. BHT resulting in increased corrosion resistance is also attributed to the inhibition of biodiesel oxidation. However, in palm biodiesel it was found that BHT is not significantly effective in raising corrosion resistance ${ }^{27}$. 
The action of TBHQ as a corrosion inhibitor in biodiesel has been studied in galvanized steel immersed in soybean biodiesel ${ }^{5}$. This effect is attributed both to a possible formation of a protective layer on the metal surface and to a possible reaction of the additive with the oxidation products of biodiesel resulting in the reduction of the corrosiveness of biodiesel.

The effect of additives in the corrosion inhibition of the carbon steel immersed in soybean biodiesel has been studied and it was found that propyl gallate was the most effective product ( $83 \%$ effectiveness) followed stearic acid $(75 \%)$ and Beta-carotene $(62 \%)^{28}$. This effect is attributed to the performance of the additives as antioxidants in biodiesel retarding the formation of free radicals with the consequent reduction in the corrosiveness of the biodiesel.

Regarding the effect of PY on the inhibition of corrosion resistance of steel, it was found ${ }^{30}$ that this additive reduces the corrosion of mild steel in palm oil biodiesel. This effect is attributed to the presence of the hydroxyl group which, in addition to having antioxidant activity, acts as free radical trapping agents.

In addition to synthetic phenols, natural additives can be used in biodiesel to serve two functions: corrosion inhibitors and antioxidants.

Curcumin, rosmarinic acid, thymol, gingerol, eugenol and quercetin are active compounds from various plant sources. In their structural formula there is the presence of $\mathrm{OH}$ groups, which can enable the action of these compounds as antioxidants $\mathrm{s}^{24}$. Figure 1 shows the structural formula of these compounds. In the curcumin, rosmerinic acid, gingerol, and eugenol compounds, oxygen is present through which a protective layer can be formed on the metal surface. These antioxidants are obtained from plants grown in Brazil and are easily available. The plants are generally grown by small farmers, and increased demand for these products can benefit these producers. Furthermore, as can be seen in Table 1, the cost of natural additives is generally lower than that of artificial additives, with the exception of the quercetin. This table also shows the cost of a liter of biodiesel containing these additives. In calculating these values, a cost of biodiesel of $\mathrm{Cr} \$ 3.0$ per liter and the density of $0.872 \mathrm{~g} / \mathrm{ml}$ for soybean oil was considered.

Although the effects of curcumin, rosmarinic acid and gingerol, on the oxidative stability of biodiesel have been

Table 1. Cost of additives $\left(\mathrm{R} \$ \mathrm{Kg}^{-1}\right)$ and cost of biodiesel with Additive (1000ppm) (US\$ L-1).

\begin{tabular}{|c|c|c|}
\hline Additive & $\begin{array}{l}\text { Cost of Additive } \\
\left(\mathrm{US} \$ \mathrm{Kg}^{-1}\right)\end{array}$ & $\begin{array}{l}\text { Cost of biodiesel } \\
\text { with Additive } \\
(1000 \mathrm{ppm}) \\
\left(\mathrm{US} \$ \mathrm{~L}^{-1}\right) \\
\end{array}$ \\
\hline $\begin{array}{l}\text { Rosemaryinic acid } \\
\text { (natural) }\end{array}$ & 7.44 & 0.587 \\
\hline Thymol (natural) & 8.56 & 0.589 \\
\hline Eugenol (natural) & 15.23 & 0.593 \\
\hline Curcumin (natural) & 5.14 & 0.585 \\
\hline Gingerol (natural) & 15.50 & 0.595 \\
\hline Quercetin (natural) & 25.83 & 0.605 \\
\hline TBHQ (artificial) & 24.32 & 0.603 \\
\hline BHA (artificial) & 25.33 & 0.605 \\
\hline BHT (artificial) & 22.23 & 0.601 \\
\hline
\end{tabular}

studied previously ${ }^{19,31,37}$, it is not clear how the presence of these additives affects the corrosion resistance of steel in biodiesel. Regarding the other additives, as far as is known, the effect of these additives on oxidative stability and corrosiveness of biodiesel is not clear in the literature.

The present work aims to investigate the effect of the natural organic compounds curcumin, rosmarinic acid, eugenol, gingerol, quercetin, and thymol on the oxidative stability and corrosion inhibition of soybean biodiesel. Additionally, the action of the natural additives on the corrosion resistance of carbon steel was investigated.

\section{Experimental Procedure}

\subsection{Sample preparation}

AISI 1020 carbon steel specimens were used to perform the analyses, which were prepared according to the following steps:

1. Stage: Cutting the steel plate to obtain rectangular specimens with an area of $4 \mathrm{~cm}^{2}$.

2. Stage: Drilling the $2 \mathrm{~mm}$ diameter hole close to the edge of the specimens.

3. Stage: Sanding of the specimens with silicon carbide (SiC) sandpaper with a particle size between 220 to 1200 .

4. Stage: After sanding, the specimens were washed with distilled water, acetone and again with distilled water to remove fat, grease and dirt from the sandpaper, meeting the standards SAE J1747 $7^{38}$.

5. Stage: Immersion of the specimens in a solution of $40 \mathrm{ml}$ of soy biodiesel.

6. Stage: After 90 days, the specimens were removed from the soy biodiesel solution, washed with soap and water to remove corrosion products, and then washed with distilled water and acetone.

7. Stage: In the presence of strongly adhered corrosion products, the specimens were immersed in a solution containing 5\% citric acid for a maximum time of $10 \mathrm{~s}$.

8. Stage: After being removed from the citric acid solution, the specimens were washed with distilled water to eliminate the waste of this solution, and dried with paper towels.

Figure 2 shows a flowchart of the procedure used to prepare the specimens.

The methyl soybean biodiesel sample used in the development of this study was produced in the laboratory by transesterification reaction and was used as the immersion medium. Methanol ( $85 \mathrm{~g})$ and $\mathrm{KOH}(1.5 \mathrm{~g})$ were added to a $150-\mathrm{mL}$ beaker. After stirring for $30 \mathrm{~min}$ to dissolve the $\mathrm{KOH}$, the solution was added into a $500-\mathrm{mL}$ ballon containing $300 \mathrm{~g}$ of soybean oil and this reaction was stirred for $110 \mathrm{~min}$ at $45^{\circ} \mathrm{C}$. Then the mixture was transferred to a separating funnel and allowed to rest for $1 \mathrm{~h}$ to separate the biodiesel and glycerin phases. The glycerin was removed, and the biodiesel phase was washed with hot water $\left(50^{\circ} \mathrm{C}\right)$ to remove residual alcohol, glycerin, catalyst, and other unwanted compounds. Finally, the biodiesel was filtered with anhydrous sodium sulfate previously dried in an oven for $6 \mathrm{~h}$.

The natural additives added to soy biodiesel were obtained from dried vegetable mass and the extracts were prepared using the Soxhlet method ${ }^{39}$, using methanol as a solvent. The 
<smiles>[R20]c1ccc(O)c(O)c1</smiles>

(c)<smiles>C=CCc1ccc(O)c(OC)c1</smiles>

(e)<smiles>O=c1c(O)c(-c2ccc(O)c(O)c2)oc2cc(O)cc(O)c12</smiles>

(b)<smiles>COc1cc(/C=C/C(=O)/C=C(O)/C=C/c2ccc(O)c(OC)c2)ccc1O</smiles>

(d)<smiles>CCC[C@H](O)CC(=O)CCc1ccc(O)c(OC)c1</smiles>

(f)<smiles>Cc1ccc(C(C)C)c(O)c1</smiles>

Figure 1. Strutural formula of active substance present in natural extracts used as biodiesel additives: rosemaric acid (a) ${ }^{31}$, curcumin $(b)^{32}$, eugenol $(\mathrm{c})^{33}$, gingerol $(\mathrm{d})^{34}$, quercetin $(\mathrm{e})^{35}$, and thymol $(\mathrm{f})^{36}$.

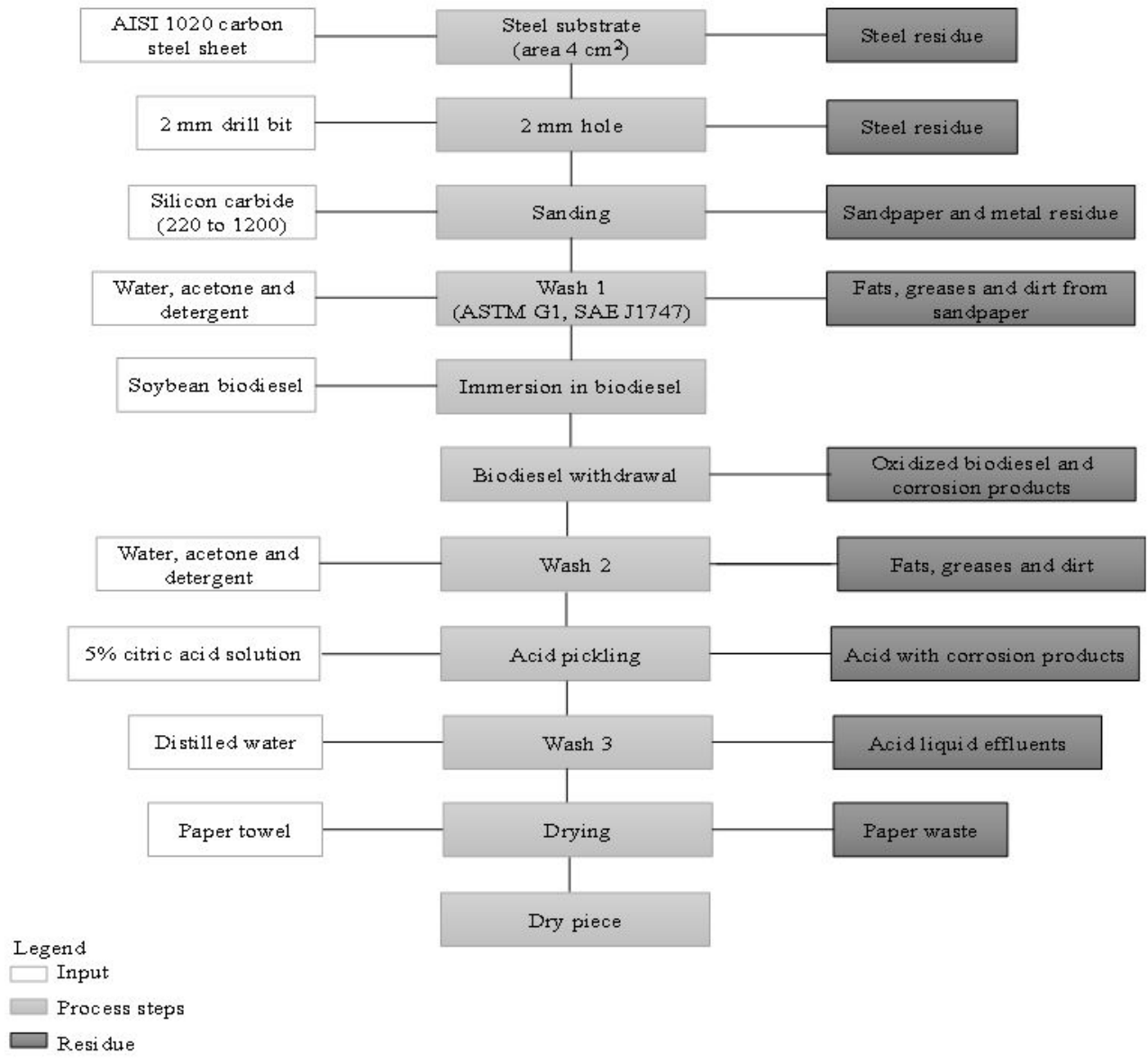

Figure 2. Flowchart of the procedure used in the preparation of the specimens. 
Table 2. Analyzed compounds and the respective sources from which they were obtained, in addition to the scientific name of the compounds.

\begin{tabular}{lcc}
\hline \multicolumn{1}{c}{ Vegetable } & $\begin{array}{c}\text { Additive } \\
\text { (main active } \\
\text { compound) }\end{array}$ & Scientific name \\
\hline Turmeric & Curcumin & Curcuma longa L \\
\hline Clove & Eugenol & Dianthus caryophyllus \\
\hline Ginger & Gingerol & Zingiber of icinalis \\
\hline Stone breaker & Quercetin & Phyllanthus niruri \\
\hline Rosemary & Rosmarinic acid & Rosmarinus officinalis \\
\hline Thyme & Thymol & Thymus vulgaris \\
\hline
\end{tabular}

additives were obtained from the extracts of the following sources: turmeric, clove, ginger, stone breaker, rosemary, and thyme. Table 2 shows the Compounds used as additives and the respective plant sources from which they were obtained, with the additives corresponding to the main components.

In the procedure for obtaining the compounds $10.00 \mathrm{~g}$ of the dried plants was weighed, wrapped in a filter paper and placed in the cellulose cartridge and then placed in the extractor. Extraction occured under heating and refluxing of the solvent in an intermittent process for a period of approximately $8 \mathrm{~h}$ until solvent clarity occured at full extraction.

The effect of the compounds as antioxidants and corrosion inhibitors in soy biodiesel was analyzed by adding $1000 \mathrm{ppm}$ of the compound to biodiesel.

There is a critical concentration of antioxidant below which the effectiveness of the antioxidant increases with increasing concentration. From that concentration, there is no improvement in antioxidant activity. It has even been reported that in most cases for a given concentration above the critical concentration, the antioxidant acts as a prooxidant and promotes the degradation reaction ${ }^{15,40}$. It is recommended that the concentration of the antioxidant be between the critical concentration and the concentration of saturation ${ }^{15}$.

The concentration of $1000 \mathrm{ppm}$ was chosen based on results published in the literature. This concentration was analyzed in studies on the effect of curcumin and gingerol on the oxidative stability of biodiesel and it was found that this concentration is sufficient to significantly increase periodic induction. The results also show that the $1000 \mathrm{ppm}$ concentration is below the saturation concentration ${ }^{19,37}$. In addition, the $1000 \mathrm{ppm}$ concentration was used in a large study ${ }^{15}$ on the effect of different artificial and natural additives on the antioxidant activity of different types of biodiesel.

However, the effect of the concentration of the additive on the oxidative stability of biodiesel depends on the type of additive $e^{41}$. Therefore, in future work, the effect of the concentration of additives on the stability and inhibition of biodiesel corrosion will be analyzed, including the determination of the critical concentration of the additives.

\subsection{Corroded surface analysis}

After the immersion test, X-ray diffraction (XRD) analysis was performed with a SHIMADZU machine and XRD-6000 model to analyze the corroded carbon steel surfaces. The image of the surface texture covered by corrosion products was captured using a TESCAN and VEGA3LMU scanning electron microscope (SEM) and OLYMPUS optical microscope, model U-25LBD. The compositional alteration of the elemental exposed surface was examined via energydispersive X-ray spectroscopy (EDS) Oxford Instruments brand and model 51-ADD0007.

\subsection{Corrosion rate and retardation efficiency of inhibitor}

The average weight loss of the triplicate coupons after the immersion was measured to quantify the metal corrosion rate and the corrosion retardation efficiency of the inhibitors using Equations 3 and 4 according to NACE Standard RP0775-2005 $5^{42}$ :

$$
\begin{aligned}
& C_{R}=\frac{K x W}{\rho x A x t} \\
& \eta=\left[\frac{\left(C_{R i}-C_{R}\right)}{T P C_{B}}\right] x 100
\end{aligned}
$$

In Equation 3, $\mathrm{C}_{\mathrm{R}}$, W, D, t, and $\mathrm{A}$ are the material corrosion rate $\left(\mu \mathrm{m} \mathrm{y}^{-1}\right)$, weight loss $(\mathrm{g})$, density of material $\left(\mathrm{g} \mathrm{cm}^{-3}\right)$, immersion time $(\mathrm{h})$, and exposed area $\left(\mathrm{cm}^{2}\right)$, respectively. In Equation $4, \eta, \mathrm{C}_{\mathrm{R}}$, and $\mathrm{C}_{\mathrm{Ri}}$ represent inhibition efficiency, material corrosion rate in $\mathrm{B} 100$, and corrosion rate in additivedoped $\mathrm{B} 100$, respectively.

\subsection{Rancimat and peroxide value}

The oxidative stability (induction period) of biodiesel was measured using a Rancimat Metrohm model 743 in accordance with EN 14112 standard ${ }^{43}$.

The methodology for determining the peroxide value began with the weighing of $5.00 \pm 0.05 \mathrm{~g}$ of the soybean biodiesel sample in a $250 \mathrm{~mL}$ Erlenmeyer. Then, $0.5 \mathrm{ml}$ of the saturated $10 \%$ potassium iodide solution was added and left to stand with gentle stirring for about 1 minute. After that, $30 \mathrm{~mL}$ of a mixture of acetic acid and chloroform $(3: 2)$ was added. Agitation is required for complete solubilization to occur. Then, $30 \mathrm{~mL}$ of distilled water was added and titration started with the $(0.1 \mathrm{~N})$ sodium thiosulfate solution until the yellow color completely disappeared, then $0.5 \mathrm{~mL}$ of starch indicator (1\%) solution was added and the solution took on a bluish character. Titration was continued until the blue color had completely disappeared. In parallel, a blank test was also performed following the same method. The peroxide value was calculated using Equation 5:

Peroxidevalue $=\frac{(\mathrm{B}-\mathrm{A}) \times N \times f \times 100}{m}$

where A is the volume $(\mathrm{mL})$ of the standard volumetric $\mathrm{Na}_{2} \mathrm{~S}_{2} \mathrm{O}_{3}$ solution used for the blank test; $\mathrm{B}$ is the volume $(\mathrm{mL})$ of the standard volumetric $\mathrm{Na}_{2} \mathrm{~S}_{2} \mathrm{O}_{3}$ solution used for the sample titration; $\mathrm{N}$ is the normal concentration of the standard volumetric $\mathrm{Na}_{2} \mathrm{~S}_{2} \mathrm{O}_{3}$ solution used; $f$ is the correction factor; and $\mathrm{m}$ is the mass of the sample ( $\mathrm{g}$ ).

\subsection{Kinematic viscosity, water content and acid value}

The acid value was measured according ASTM D 1293-9944 (indicated by the $\mathrm{pH}$ value of distilled water in contact with biodiesel). The sample was titrated with $\mathrm{NaOH}\left(0.1 \mathrm{~mol} \mathrm{~L}^{-1}\right)$ using 
phenolphthalein as indicator. The parameter acid value is expressed as the amount (mg) of sodium hydroxide needed to neutralize one gram of the biodiesel.

The kinematic viscosity of biodiesel was obtained according to the ASTM D445-03 Standard Test Method ${ }^{45}$. In order to obtain this parameter, a Modular Rheometer Physica model MCR50 was used, at temperature of $40{ }^{\circ} \mathrm{C}$. The Experimental conditions were established using the software RHEO 2000 Version 2.6®, as described: a) Analysis time: 120 seconds for ascending curve and 120 seconds for descending curve; b) Shear gradient: from 0 to $125 \mathrm{rpm}$ $(3.75(1 / \mathrm{s})$ to $750(1 / \mathrm{s})$.

The water content in biodiesel was obtained according to the ASTM D6304-16 Standard Test Method ${ }^{46}$. This method consists of determining the amount of water in the biodiesel through chemical and electrochemical reactions, spontaneous and induced, developed in a solution rich in iodide and sulfur dioxide. A coulumetric titrator model C20 from Mattler Toledo was used. The coulumetric reagent used was HYDRANALTM Coulomat AG.

\section{Results and Discussion}

\subsection{Physicochemical properties of soybean biodiesel}

Table 3 shows parameters related to the physicochemical properties of the recently produced soy biodiesel and after 90 days. This table also displays the specifications established by the National Agency of Petroleum, Natural Gas, and Biofuels (ANP) in accordance to Resolution 14/2012.

Regarding the physicochemical parameters analyzed, Table 3 shows that the soybean biodiesel used in the present work is within the limits permitted by the ANP resolution, even after 90 days storage.

The acid value indicates the amount of free fatty acids in the biodiesel. The increase in acid values may favor corrosion of the metal components of the engine ${ }^{47}$. Regarding the effect of adding natural additives on the acid value of biodiesel, it was observed that the addition of curcumin does not significantly affect this parameter ${ }^{19}$, and the relationship between this effect and the oxidative stability of the biodiesel has not been established. The relationship between the effect of ginger on the oxidative stability of biodiese ${ }^{37}$ has also not been established.

A kinematic viscosity value above the limit established by ANP's Resolution 14/2012 can cause problems in the operation of an engine, such as increased coking of the injector, plugging of the fuel filter, and sticking of moving parts ${ }^{9}$. With the increase in storage time, see Table 3, there is an increase in kinematic viscosity, which is attributed to the formation of high molecular-weight polymeric compounds ${ }^{48}$. Regarding the effect of additives on the kinematic viscosity, it was found that the addition of additives did not cause a significant change in the viscosity of B-100, and it is not possible to establish a relationship between this effect and oxidative stability, as well as the corrosivity of biodiesel. With the exception of curcumin, the presence of additives did not increase the kinematic viscosity of biodiesel. The presence of curcumin caused a slight increase in kinematic
Table 3. Physicochemical parameters of the recently produced soy biodiesel (B100-0 days) and after 90 days (B100-90 days).

\begin{tabular}{lcccc}
\hline \multicolumn{1}{c}{ Properties } & Unity & $\begin{array}{c}\mathrm{B} 100-0 \\
\text { days }\end{array}$ & $\begin{array}{c}\mathrm{B} 100-90 \\
\text { days }\end{array}$ & $\begin{array}{c}\text { Limit } \\
\text { (ANP) } \\
\text { Resolution } \\
14 / 2012\end{array}$ \\
\hline $\begin{array}{l}\text { Kinematic } \\
\text { viscosity at } 40{ }^{\circ} \mathrm{C}\end{array}$ & $\mathrm{mm}^{2} / \mathrm{s}$ & 4.55 & 5.34 & $3.0-6.0$ \\
\hline $\begin{array}{l}\text { Maximum water } \\
\text { content }\end{array}$ & $\mathrm{mg} / \mathrm{Kg}$ & 192 & 250 & 500 \\
\hline Acid values & $\mathrm{mgKOH} / \mathrm{g}$ & 0.15 & 0.19 & 0.5 \\
\hline
\end{tabular}

Table 4. Biodiesel induction period (IP) values in the absence and presence of $1000 \mathrm{ppm}$ additives and oxidative stability efficiency $(\eta)$.

\begin{tabular}{lcc}
\hline \multicolumn{1}{c}{ Additive } & IP $(\mathrm{h})$ & $\eta(\%)$ \\
\hline----- & 3.79 & - \\
\hline Curcumin & 7.29 & 92 \\
\hline Eugenol & 5.91 & 56 \\
\hline Gingerol & 6.55 & 73 \\
\hline Quercetin & 7.01 & 85 \\
\hline Rosmarinic acid & 7.10 & 87 \\
\hline Thymol & 7.25 & 91 \\
\hline$\eta$ - oxidative stability efficiency &
\end{tabular}

viscosity after 90 days of storage, with the biodiesel viscosity increasing from $5.34 \mathrm{~mm}^{2} / \mathrm{s}$ to $5.64 \mathrm{~mm}^{2} / \mathrm{s}$, while staying within the limit established by ANP's Resolution 14/2012. This effect is consistent with the results obtained by De Souza et al. ${ }^{19}$.

The presence of water can damage the oxidative stability of biodiesel by favoring hydrolysis and the proliferation of microorganisms ${ }^{19}$. As can be seen in Table 3, there was water absorption in biodiesel during storage, however, within the limit established by the ANP Resolution 14/2012. With the addition of the additives, it was found that there was no significant change in the water content of both the newly obtained biodiesel and the biodiesel stored for 90 days.

\subsection{Effect of additives on oxidative stability of soybean biodiesel}

The effect of additives on the oxidative stability of biodiesel (B100) was evaluated by determining the induction period. Table 4 shows the values of the biodiesel induction period in the absence and presence 1000 ppm of the additives. These values obtained by the Rancimat method at $110^{\circ} \mathrm{C}$ show an induction period of B100 of $3.79 \mathrm{~h}$. According to $\mathrm{N} 14214^{49}$ the minimum time for biodiesel to oxidize is around 6 hours which indicates that the biodiesel analyzed in the present work is appropriate for the addition of antioxidants. The additives analyzed here increase the induction period of $\mathrm{B} 100$ indicating that they act as antioxidants. This antioxidant effect depends on the molecular structure of the active substances present in natural extracts, which are shown in Figure 1. These substances have aromatic systems that are effective in capturing free radicals ${ }^{19}$. Several additives that have a suitable antioxidant activity have in the aromatic system $\mathrm{OH}$ and / or $\mathrm{NH}$ groups, which release atoms to the free radical $^{15,16}$, and a larger amount of $\mathrm{OH}$ group tends to elevate the antioxidant effect. 
The high antioxidant activity of curcumin it can be attributed to two structural subnits: methylene $\alpha$ from the carbonyls and the phenolic hydroxyls. In both cases the antioxidant activity is related to the donation of hydrogen radical which reacts with reactive oxygen species (ROS) and neutralizes possible cellular damage than resulting from the presence of these intermediates ${ }^{50}$ (Figure 3).

Among the additives analyzed, curcumin from turmeric extract is the one with the highest $\mathrm{OH}$ group number in the aromatic system which is consistent with the longest induction period obtained for this additive. The higher induction period caused by the addition of thyme to biodiesel may be related with the structure molecular of its principal active substance the thymol (Figure 1). This phenol has one isopropyl group in ortho and one methyl group in meta position to the hydroxyl. The high antioxidant activity of this active compound can be explained by the inductive electron donor effect by isopropyl and methyl groups that makes it easier to release hydrogen by the hydroxyl group.

Stone breaker extract and rosemary extract also have antioxidant compounds (quercetin and rosmarinic acid) with a greater number of $\mathrm{OH}$ groups in their aromatic system, resulting in a longer induction period than the addition of ginger and clove extracts that contain a smaller number of this group in their main active compounds (gingerol and eugenol). The longer induction period of gingerol compared to eugenol may be related to the longer length of the gingerol chain, however, it is not clear how this difference can affect the induction period.

Among the additives analyzed only the addition of extract the turmeric (curcumin), thyme (thymol), rosemary (rosmarinic acid), and stone breaker (quercetin) allowed the analyzed biodiesel to reach the induction period of $7.29 \mathrm{~h}$, $7.25 \mathrm{~h}, 7.10$, and $7.01 \mathrm{~h}$, accepted by the current norms. However, the effect of the additive on making the biodiesel induction period accepted by the standards depends on the biodiesel induction period in the absence of the additive. The induction period is very sensitive to storage time, and this parameter decreases with the storage time of biodiesel.

The peroxide values of B100 in the absence and presence of rosmarinic acid, eugenol and curcumin are shown in Table 5. These results show that the presence of additives decreases the peroxide value of B100, and this effect is most intense in the sample containing curcumin, which has a negligible peroxide value.

The peroxide value (PV) indicates the amount of hydroperoxide that initiates the oxidation process and is related to the extent of primary oxidation ${ }^{11,51}$. A lower PV indicates greater stability of the initial oxidation state of the biodiesel. Therefore, the results in Table 5 indicate that the addition of the additive inhibits the early stages of oxidation of the biodiesel. This effect is most intense in the sample containing curcumin, which has a negligible peroxide value.

A lower PV value is related to a lower amount of lipid peroxides which are primary lipid oxidation products. However, PV determination is susceptible to interference through molecular oxygen and reactions of liberated iodine with other components in the system ${ }^{55,56}$.

Comparing the PV values with the induction period in Table 4, it can be seen that the sample with curcumin that exhibits a greater induction period has a lower PV, while the sample with eugenol that exhibits a lesser induction period has a greater PV. These results therefore show that a lesser extent of primary oxidation contributes to a greater oxidative stability of the analyzed biodiesel.

\subsection{Effect of additives on corrosion resistance of soybean biodiesel}

Figure 4 shows the corrosion rate of carbon steel in $\mathrm{B} 100$ in the absence and presence of $1000 \mathrm{ppm}$ of different additives. Table 6 shows the corrosion inhibition efficiency of these additives. These results, obtained through mass loss measurements, show that the corrosion resistance of carbon steel increases with the presence of the analyzed additives showing that they act as corrosion inhibitors. Curcumin and rosmarinic compounds have the highest protective effect,

Table 5. Peroxide values in pure biodiesel sample (B100) and samples with additives.

\begin{tabular}{lcc}
\hline \multicolumn{1}{c}{ Sample } & ppm & Peroxide value $\left(\mathrm{mEq} \mathrm{Kg}^{-1}\right)$ \\
\hline B100 & 0 & 15.96 \\
\hline Rosmarinic acid & 2000 & 13.3 \\
\hline Eugenol & 2000 & 14.8 \\
\hline Curcumin & 2000 & 0 \\
\hline
\end{tabular}

Table 6. Corrosion inhibition efficiency $(\eta)$ of these additives on carbon steel in B100 in the absence and presence of $1000 \mathrm{ppm}$ of different additives.

\begin{tabular}{lc}
\hline \multicolumn{1}{c}{ Simple } & $\eta(\%)$ \\
\hline B100 & - \\
\hline Rosmarinic acid & 60.5 \\
\hline Curcumin & 61.8 \\
\hline Eugenol & 49.8 \\
\hline Gingerol & 55.8 \\
\hline Quercetin & 50.5 \\
\hline Thymol & 45.3 \\
\hline$\eta$ - Corrosion inhibition efficiency &
\end{tabular}

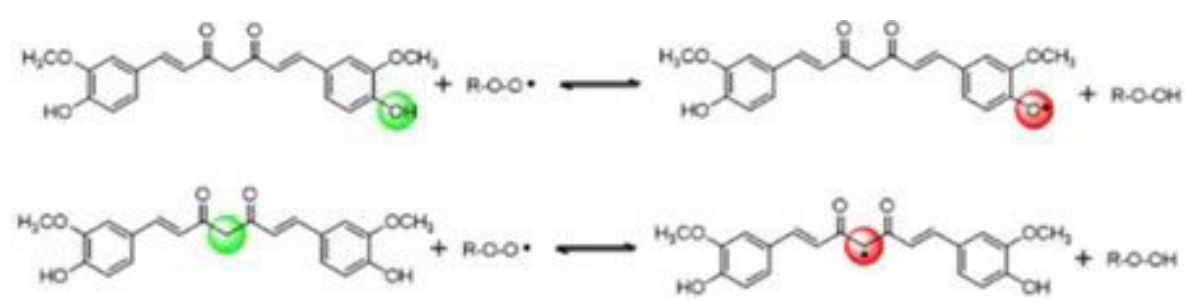

Figure 3. Curcumin action as an antioxidant and anticorrosive. 


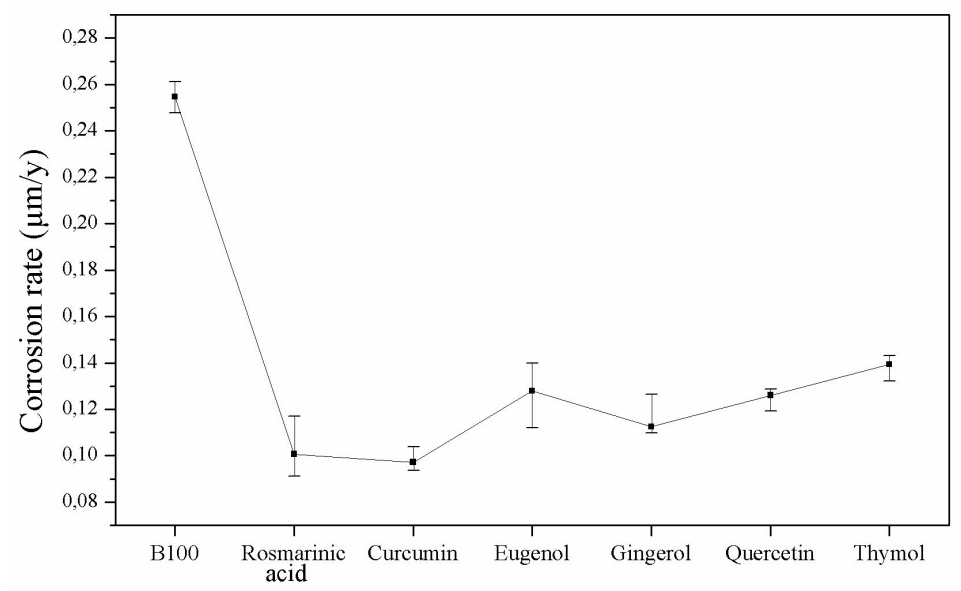

Figure 4. Corrosion rate of carbon steel in B100 in the absence and presence of $1000 \mathrm{ppm}$ of different additives.
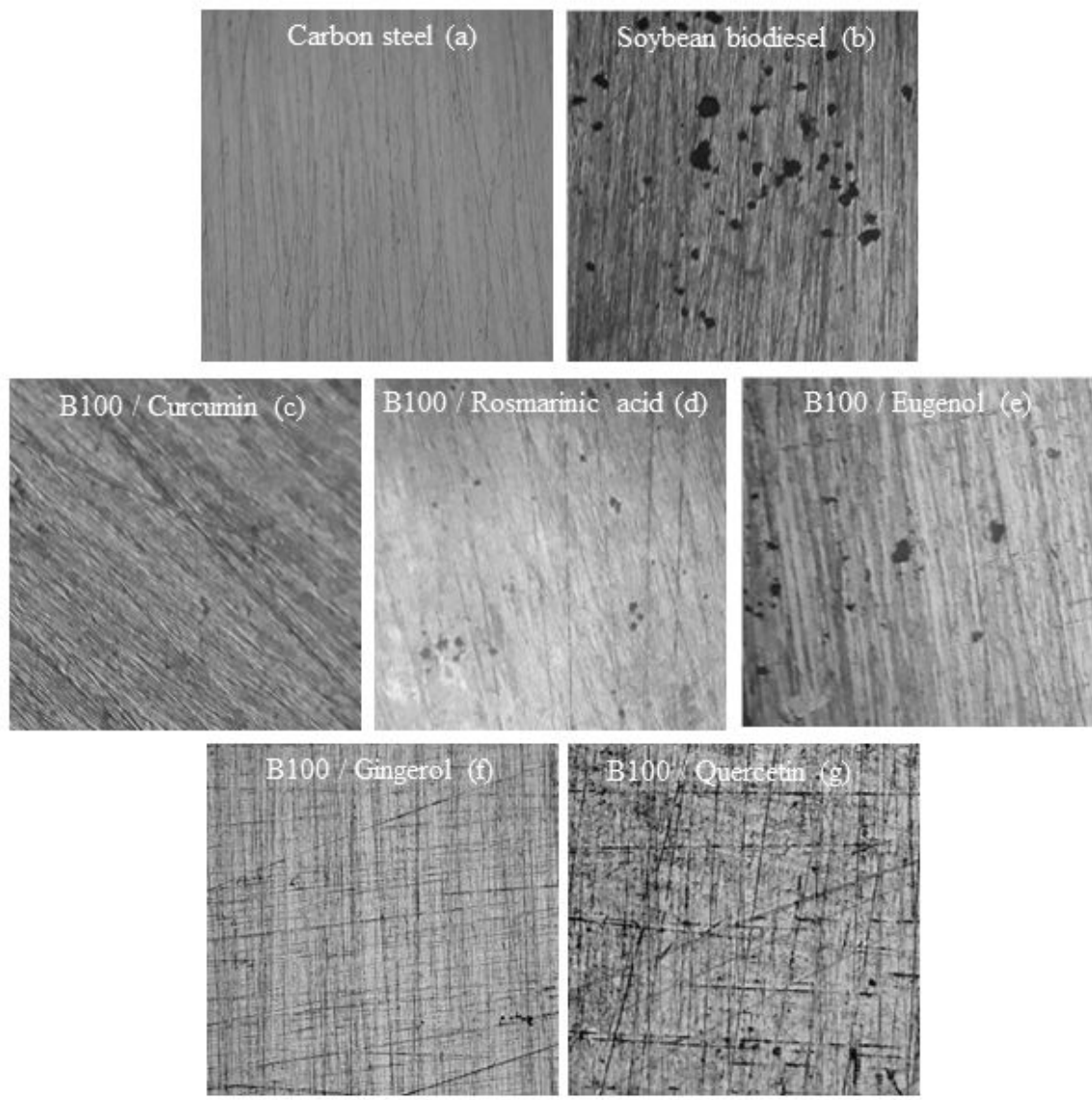

Figure 5. Appearances of carbon steel coupons observed by light microscopy after immersion in B100 in the absence and presence of various additives.

while the corrosion rates of the other additives are within the margin of error.

Figure 5 illustrates the appearance of carbon steel coupons observed by optical microscopy before (Figure 5a) and after immersion for 90 days in B100 in the absence and presence of various additives. The sample exposed to B100 in the absence of additive exhibit severe corrosion attack additives (Figure 5b). The degradation of the steel carbon surface can be attributed to a chemical interaction between the metal surface and the biodiesel. However, the degree of corrosion attack is comparatively less in the presence of additives curcumin and rosmarinic (Figures $5 \mathrm{c}, \mathrm{d}$ ).

The SEM micrographs of carbon steel surface after B100 exposure for 90 days in the absence and presence of additives are illustrated in Figure 6. The carbon steel surfaces immersed in B100 in the absence of additives are 

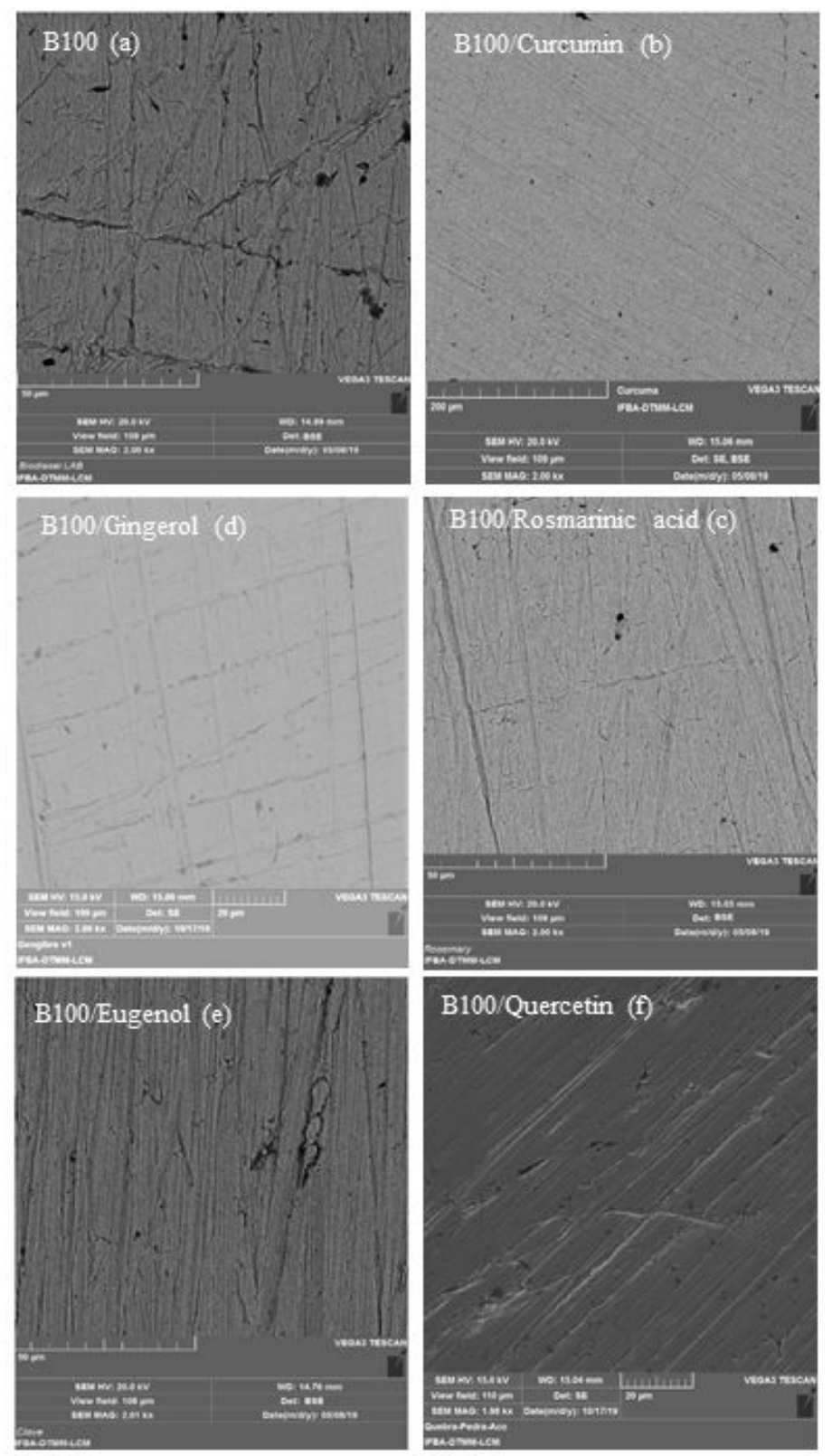

Figure 6. SEM micrographs of carbon steel surface after B100 exposure for 90 days in the absence and presence of additives.

severely damaged by corrosion attack with the presence of large corrosion pits (Figure 6a). The SEM images (Figures 6b-d) of samples immersed in B100 containing additives exhibit a reduction in corrosion attack with the presence of significantly smaller corrosion pits. These pits are smaller in SEM image of samples immersed in presence of curcumin (Figure 6b) which is consistent with the mass loss tests that show a lower corrosion rate for the samples immersed in the presence of this additive.

The EDS analysis results of the carbon steel surface after immersion in B100 in the absence and presence of different additives is shown in Figure 7. Upon exposure to biodiesel, ferrous metal forms iron oxides, which are nonprotective corrosion products ${ }^{52}$. A greater quantity of these products therefore indicates a higher rate of corrosion. The addition of additives to B100 decreases the concentration of iron oxides (Figures 7b-d) which indicates a reduction in corrosion attack. This decrease is more intense with the addition of curcumin and rosmarinic acid, which is consistent with previous findings indicating that these additives are more efficient in increasing corrosion resistance than eugenol.

Figure 8 shows the XRD patterns of the carbon steel surface before and after immersion in B100 in the absence and presence of additives. The diffraction peaks corresponding to corrosion products are not clearly identified in the XRD patterns. However, the XRD patterns indicate the location of possible corrosion products of carbon steel in biodiesel according to the standard sheet for these compounds 


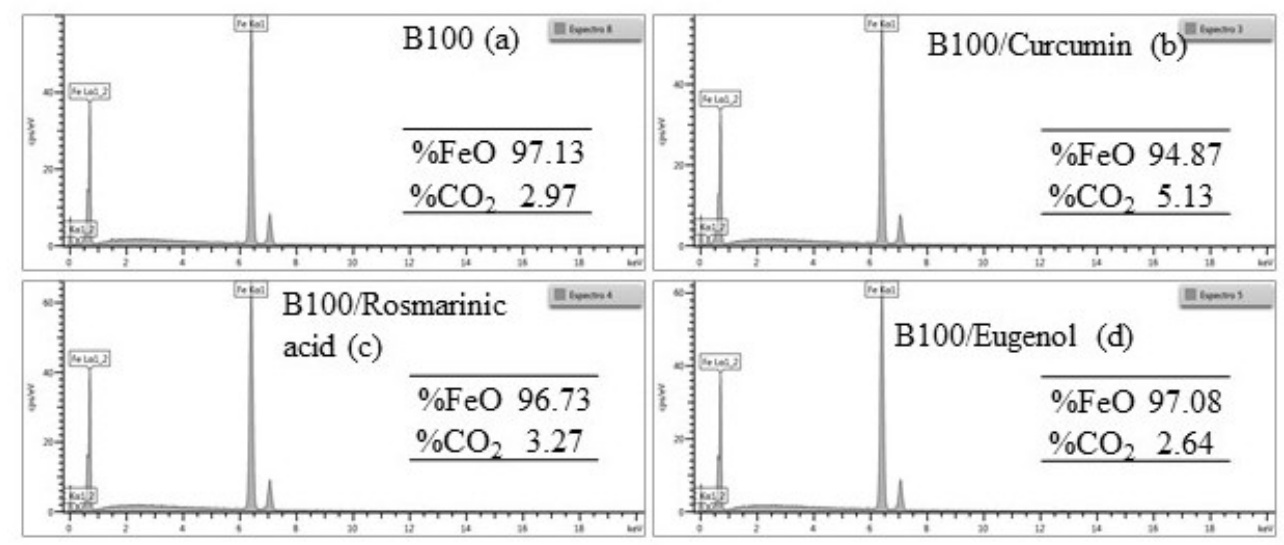

Figure 7. EDS analysis results of the carbon steel surface before and after immersion in B100 in the absence and presence of different additives.
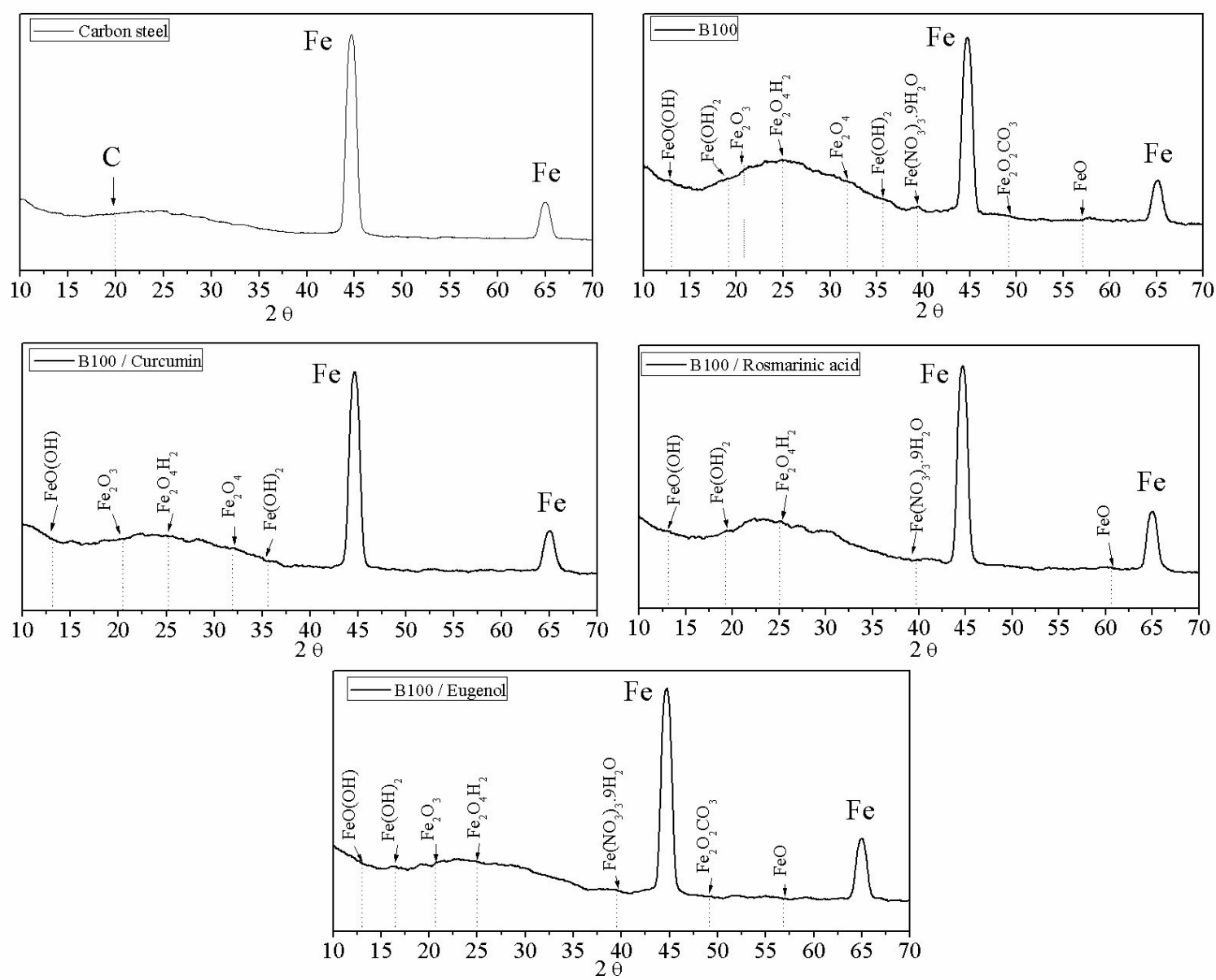

Figure 8. XRD patterns of the carbon steel surface before and after immersion in B100 in the absence and presence of additives.

$(\mathrm{COD} 7204904 \mathrm{Fe})^{27}$. The XRD patterns show that the intensity corresponding to $\mathrm{Fe}_{2} \mathrm{O}_{3}, \mathrm{Fe}_{2} \mathrm{O}_{4} \mathrm{H}_{2}$, and $\mathrm{Fe}_{2} \mathrm{O}_{4}$, around 20.5 ${ }^{\circ}$, $25^{\circ}$, and $31.8^{\circ}$, respectively, is higher in the XRD patterns corresponding to the absence of additives. This indicates a lower presence of corrosion products in the B100 containing additives which is consistent with the increased corrosion resistance caused by the presence of additives. However, it is not possible through the XRD patterns to clearly state the effect of the different additives.

The corrosion mechanism of carbon steel in contact with soy biodiesel is based on oxygen and $\mathrm{H}^{+}$reduction reactions in the cathodic region and on the oxidation reaction from 
Fe to $\mathrm{Fe}^{2+}$ at the anode. While the reduction reaction of oxygen occurs at the water droplet-biodiesel interface due to the higher concentration of oxygen in that region, the oxidation reaction occurs on the steel surface in contact with the central part of the water droplet ${ }^{22}$.

Previously in the introduction, it was seen that the corrosion products from the reaction of the Fe ions with the substances $\mathrm{O}_{2}, \mathrm{CO}_{2}$ and $\mathrm{H}_{2} \mathrm{O}^{23,24}$, result in the formation of oxides, carbonates and hydroxides, respectively. Thus, the corrosion mechanism is related to the presence of substances that act as a source of $\mathrm{H}^{+}$.

When water is in contact with biodiesel, it has two effects associated with its presence: it causes the occurrence of corrosion by differential aeration and the increase in ionic conductivity that results in hydrolysis reactions for the formation of fatty acids ${ }^{53}$. Soybean biodiesel contains methyl esters and oxygenated chemicals, including alcohols, carbonyl chemicals and organic acids ${ }^{54}$. As methyl esters and organic substances are acidic, they act as a source of $\mathrm{H}^{+}$, contributing to the corrosion of stee ${ }^{55}$.

In the present work, the corrosion inhibition mechanism of the analyzed additives probably involves the formation of a protective adsorbed layer on steel surface ${ }^{5,27,29}$. It is also possible that the corrosion inhibition mechanism is related to the action of the additives analyzed to increase the oxidative stability of soy biodiesel ${ }^{5,28}$. According to the results obtained in relation to the induction period, the additives investigated in the present work increase the oxidative stability of soybean biodiesel. Therefore, it is possible that these additives may react with the oxidation products of biodiesel which results in the reduction in the corrosivity of biodiesel. However, the effect of additives as corrosion inhibitors could also be related to the formation of a surface protective layer.

The adsorption of a sufficient coverage of stable protective layer over metal surfaces blocks direct chemical attacks between the metal and the biodiese $\mathrm{l}^{27,29,32}$, thus increasing the corrosion resistance of metal in biodiesel. The protective capacity of this layer is related to the intensity of interaction between the atoms of the additive molecule and the metal surface. It has been found ${ }^{27}$ that the adsorption of additive molecules via heterocyclic moiety $\mathrm{N}$ atoms (protonated amine), as with the TBA, exhibits a stronger interaction compared with that via $\mathrm{OH}$ group, which results in a more protective surface layer in carbon steel. Adsorption via lone pair electron of the $\mathrm{OH}$ group, as with the BHT, is considered insufficient to form a corrosion-protective adsorbed layer on carbon steel in palm biodiese $^{27}$. However, the performance of the additive as a corrosion inhibitor depends on several factors, such as biodiesel feedstock, concentration of biodiesel in the blend, and of the metal surface in contact with biodiese ${ }^{56}$. It has been found ${ }^{29}$ that in biodiesel blend B20, which is less corrosive than palm biodiesel, the addition of BHT allows the formation of a protective film that inhibits the corrosion of carbon steel.

In the present work, the presence of the $\mathrm{OH}$ group contained in the analyzed additives may have been sufficient to form a corrosion-protective adsorbed layer on steel carbon in soybean biodiesel, which has a lower acid value than palm biodiesel and, therefore, is less corrosive $\mathrm{e}^{57}$. In the cases of curcumin, rosmarinic acid, gingerol, and quercetin additives the formation of the protective layer can also occur through the electrons present in the oxygen which can result in a more protective adsorbed layer. Analyzing the values of inhibition efficiency in Table 3 for thymol and eugenol containing only hydroxyl, it can be observed that thymol exhibits an inhibition efficiency lower than that of oxygen-containing additives, however, the values of the inhibition efficiency of eugenol is within the margin of error of the other additives with the exception of rosmarinic acid.

Regarding the effect that the reaction of the additive with the oxidation products of biodiesel can have on the corrosivity of biodiesel, curcumin, as shown in Table 6 , is the additive with the best oxidative stability performance and together with rosmarinic acid. it promotes the highest corrosion resistance. This behavior is consistent with the fact that greater oxidative stability of biodiesel implies a decrease in the acidity and peroxide value of biodiesel resulting in a lower rate of corrosion ${ }^{5,54,58}$. On the other hand, thymol which, with the exception of curcumin, promotes oxidative stability superior to that of other additives, is the least efficient corrosion inhibitor. These results therefore show that the effect of the adsorbed layer may predominate over the effect of the additive on oxidative stability. As can be seen, the mechanism through which the additive acts as a corrosion inhibitor is complex and the analysis of the interaction between the atoms of the molecules of the additives and the metallic surface is not enough to clarify this mechanism. However, this will be attempted in future work.

\section{Conclusion}

The addition of $1000 \mathrm{ppm}$ of rosmarinic acid, curcumin, gingerol, eugenol, quercetin, or thymol natural additives increases the induction period (IP) of soybean biodiesel. These results indicate that the addition of any of these additives increases the oxidative stability of soybean biodiesel. However, it was only with the addition of curcumin, thymol, rosmarinic acid or quercetin that the analyzed biodiesel reached the induction period exceeding $6 \mathrm{~h}(7.29,7.25,7.10$ and $7.01 \mathrm{~h}$, with a 92, 91,87 , and $85 \%$ increase over pure biodiesel IP), accepted by the current norms, considering that biodiesel analyzed has an IP of $3.79 \mathrm{~h}$ in the absence of additives.

The results obtained through measurements of mass loss and observation by optical microscopy and scanning electron microscopy show that the addition of 1000 ppm of additives extracted from rosemary, turmeric, ginger, clove, and stone breaker increases the corrosion resistance of carbon steel (AISI 1020) after 90 days of soaking in soybean biodiesel. The additives perform similarly in relation to the inhibition of corrosion. Curcumin (turmeric extract) and rosmarinic acid (rosemary), perform slightly better while thymol has a slightly lower performance than the other additives.

\section{Acknowledgments}

The authors thank the financial support of CAPES and CNPq and the technical support of IFBA-DTMM-LCM.

\section{References}

1. Beltrão NEM, Oliveira MIP. Oleaginosas e seus óleos: vantagens e desvantagens para produção de biodiesel. Campina Grande: Embrapa Algodão; 2008. 28 p. [Portuguese] 
2. Ferrari RA, Oliveira VS, Scabio A. Biodiesel de soja - taxa de conversão em esteres etílicos, caracterização físico química e consumo em gerador de energia. Quim Nova. 2005;28(1):19-23.

3. Dunn R. Analysis of oxidative stability of methyl soyate by pressurized differential scanning calorimetry. ASABE. 2000;43(5):1203-8.

4. Ferrari RA, Oliveira VS, Scabio A. Oxidative stability of biodiesel from soybean oil fatty acid ethyl esters. Science Agricultury. 2005;62(3):291-5.

5. Fernandes DM, Montes RHO, Almeida ES, Nascimento AN, Oliveira PV, Richter EM, et al. Storage stability and corrosive character of stabilised biodiesel exposed to carbon and galvanised steels. Fuel. 2013;107:608-14.

6. Kamalesh AS, Purnanand VB. Biodiesel properties and automotive system compatibility issues. Renew Sustain Energy Rev. 2015;41:777-98.

7. Pantoja SS, Conceição LRV, Costa CEF, Zamian JR, Rocha Filho GN. Oxidative stability of biodiesels produced from vegetable oils having different degrees of unsaturation. Energy Convers Manage. 2013;74:293-8.

8. Pullen J, Saeed K. Experimental study of the factors affecting the oxidation stability of biodiesel FAME fuels. Fuel Process Technol. 2014;125:223-35.

9. Jakeria MR, Fazal MA, Haseeb ASMA. Influence of different factors onthe stability of biodiesel: a review. Renew Sustain Energy Rev. 2014;30:154-63.

10. Monyem A, Van Gerpen JH. The effect of biodiesel oxidation on engine performance and emissions. Biomass Bioenergy. 2001;20(4):317-25.

11. Saluja RK, Kumar V, Sham R. Stability of biodiesel-a review. Renew Sustain Energy Rev. 2016;62:866-81.

12. Karavalakis G, Bakeas E, Stournas S. Influence of oxidized biodiesel blends on regulated and unregulated emissions from a diesel passenger car. Environ Sci Technol. 2010;44:5306-12.

13. Varatharajan K, Cheralathan M. Influence of fuel properties and composition on NOx emissions from biodiesel powered diesel engines: a review. Renew Sustain Energy Rev. 2012;16:3702-10.

14. Sgroi M, Bollito G, Saracco G, Specchia S. BIOFEAT: biodiesel fuel processor for a vehicle fuel cell auxiliary power unit - study of the feed system. J Power Sources. 2005;149:8-14.

15. Varatharajana K, Pushparanib DS. Screening of antioxidant additives for biodiesel fuels. Renew Sustain Energy Rev. 2018;82:2017-28.

16. Jain S, Sharma MP. Review of different test methods for the evaluation of stability of biodiesel. Renew Sustain Energy Rev. 2010;14(7):1937-47.

17. Araújo SV, Luna FMT, Rola EM Jr, Azevedo DCS, Cavalcante CL Jr. A rapid method for evaluation of the oxidation stability of castor oil FAME: influence of antioxidant type and concentration. Fuel Process Technol. 2009;90(10):1272-7.

18. Lawana I, Zhoua W, Garbaa ZN, Zhanga M, Yuana Z, Chen L. Critical insights into the effects of bio-based additives on biodiesels properties. Renew Sustain Energy Rev. 2018;102:83-95.

19. Sousa LS, Moura CVR, Oliveira JE, Moura EM. Use of natural antioxidants in soybean biodiesel. Fuel. 2014;134:420-8.

20. Fazal MA, Haseeb A, Maskuji HH. Comparative corrosive characteristics of petroleum diesel and palm biodiesel for automotive materials. Fuel Process Technol. 2010;91:1308-15.

21. Hoan AT, Tabatabaei M, Aghbashlo A. A review of the effect of biodiesel on the corrosion behavior of metals/alloys in diesel engines. Energy Sources. 2019;42(23):2923-43.

22. Wang W, Jenkins PE, Ren Z. Electrochemical corrosion of carbon steel exposed to biodiesel/simulated seawater mixture. Corros Sci. 2012;57:215-9.

23. Jin D, Zhou X, Wu P, Jiang L, Ge G. Corrosion behavior of ASTM 1045 mild steel in palm biodiesel. Renew Energy. 2015;81:457-63
24. Fazal MA, Haseeb A, Masjukin HH. Effect of temperature on the corrosion behavior of mild steel upon exposure to palm biodiesel. Energy. 2011;36:3328-34.

25. Cursaru DL, Brănoiu G, Ramadan I, Miculescu F. Degradation of automotive materials upon exposure to sunflower biodiesel. Ind Crops Prod. 2014;54:149-58.

26. Bentiss F, Lebrini M, Vezin H, Lagrenée M. Experimental and theoretical study of 3-pyridyl-substituted 1,2,4-thiadiazole and 1,3,4-thiadiazole as corrosion inhibitors of mild steel in acidic media. Mater Chem Phys. 2004;87(1):18-23.

27. Fazal MA, Sazzad BS, Haseeb ASMA, Masjuki HH. Inhibition study of additives towards the corrosion of ferrous metal in palm biodiesel. Energy Convers Manage. 2016;122:290-7.

28. Santana PMB, Meira M, Tentardini EK. Effects of adding some natural substances to biodiesel to control its effect on carbon steel corrosion. Mater Res. 2015;18:164-9.

29. Deyab MA. The inhibition activity of butylated hydroxytoluene towards corrosion of carbon steel in biodiesel blend B20. J Taiwan Inst Chem Eng. 2016;60:369-75.

30. Fazal MA, Jakeria MR, Haseeb A, Rubaiee S. Effect of antioxidants on the stability and corrosiveness of palm biodiesel upon exposure of different metals. Energy. 2017;135:220-6.

31. Oliveira TFV. Características químicas e microbiológicas do açafrão-da-terra (Curcuma longa L). [Trabalho de conclusão de curso]. Apucarana: Universidade Tecnológica do Paraná; 2017. [Portuguese]

32. Morais SM, Cavalcanti ESB, Costa SMO, Aguiar LA. Ação antioxidante de chás e condimentos de grande consume no Brasil. Rev Bras Farmacogn. 2009;19(1B):315-20.

33. Arújo RP, Morais SM. Plantas medicinais para controle da obesidade. Temas em Saúde. 2018;18(2):289-313.

34. Lima FO. Estudo comparative da bioatividade de compostos fenólicos em plantas medicinais. [thesis]. Santa Maria: Universidade Federal de Santa Maria; 2013. [Portuguese]

35. Del Ré PV, Jorge N. Especiarias como antioxidantes naturais: aplicações em alimentos e implicação na saúde. Rev Bras P1 Med. 2012;14(2):389-99.

36. Alagawany M, Farag MR, Abdelnour SA, Elnesr SS. A review on the beneficial effect of thymol on health and production of fish. Rev Aquacult. 2021;13(1):632-641.

37. Devi A, Das VK, Deka D. Ginger extract as a nature based robust additive and its influence on the oxidation stability of biodiesel synthesized from non-edible oil. Fuel. 2017;187:306-14.

38. SAE: SOCIETY OF AUTOMOTIVE ENGINEERS. J1747 - Recommended methods for conducting corrosion tests in hydrocarbon fuels or their surrogates and their mixtures with oxygenated additives. Warrendale: SAE International; 2013.

39. Mohammadpour H, Sadrameli SM, Eslami F, Asoodeh A. Optimization of ultrasound-assisted extraction of Moringa peregrina oil with response surface methodology and comparison with Soxhlet method. Ind Crops Prod. 2019;131:106-16.

40. Gordon M. The mechanism of antioxidant action in vitro. In: Hudson BJF, editor. Food antioxidants. London: Elsevier Publications; 1990. p. 1-18.

41. DeMan JM. Principles of food chemistry. Gaithersburg: Aspen Publishers, Inc; 1999.

42. NACE INTERNATIONAL. RP0775-2005 - Preparation, installation, analysis, and interpretation of corrosion coupons in oilfield operations. Houston: NACE International; 2005.

43. EN: EUROPEAN STANDARD. EN14112 - Fat and oil derivatives - Fatty Acid Methyl Esters (FAME) - determination of stability (accelerated oxidation test). Brussels: CEN; 2003.

44. ASTM: AMERICAN SOCIETY FOR TESTING AND MATERIALS. ASTM D1293-99 - Standard test methods for pH of water. West Conshohocken: ASTM International; 1999.

45. ASTM: AMERICAN SOCIETY FOR TESTING AND MATERIALS. ASTM D445-03 - Standard test method for kinematic viscosity of transparent and opaque liquids (the 
calculation of dynamic viscosity). West Conshohocken: ASTM International; 2003.

46. ASTM: AMERICAN SOCIETY FOR TESTING AND MATERIALS. ASTM D6304-16 - Standard test method for determination of water in petroleum products, lubricating oils, and additives by coulometric karl fischer titration. West Conshohocken: ASTM International; 2016.

47. Singh SP, Singh D. Biodiesel production through the use of different sources and characterization of oils and their esters as the substitute of diesel: a review. Renew Sustain Energy Rev. 2010;14:200-16.

48. Halvorsen BL, Blomhoff R. Validation of a quantitative assay for the total content of lipophilic and hydrophilic antioxidants in foods. Food Chem. 2011;27:761-8.

49. EN: EUROPEAN STANDARD. EN14214 - Automotive fuels. Fatty Acid Methyl Esters (FAME) for diesel engines. (requirements and test methods). Brussels: CEN; 2003.

50. Sueth-Santiago V, Mendes-Silva GP, Decoté-Ricardo D, Lima MEF. Curcumina, o pó dourado do açafrão-da-terra: introspecções sobre química e atividades biológicas. Quim Nova. 2015;38:538-52.

51. Yildiz G, Wehling RL, Cuppett SL. Comparison of four analytical methods for the determination of peroxide value in oxidized soybean oils. J Am Oil Chem Soc. 2003;80(2):103-7.
52. Fazal MA, Rubaiee S, Al-Zahrani A. Overview of the interactions between automotive materials and biodiesel obtained from different feedstocks. Fuel Process Technol. 2019;196:106-78.

53. Díaz-Ballote L, López-Sansores JF, Maldonado-López L, Garfias-Mesias FL. Corrosion behavior of aluminum exposed to a biodiesel. Electrochem Commun. 2009;11(1):41-4.

54. Peng C, Lan C, Dai Y. Speciation and quantification of vapor phases in soy biodiesel and waste cooking oil biodiesel. Chemosphere. 2006;65:2054-2562.

55. Boonyongmaneerat Y, Sukjamsri C, Sahapatsombut U, Saenapitak S, Sukkasi S. Investigation of electrodeposited Ni-based coatings for biodiesel storage. Appl Energy. 2011;88:909-13.

56. Lovaas E. A Sensitive spectrophotometric method for lipid hydroperoxide determination. Ibid. 1992;69:777-83.

57. Fazal MA, Suhaila NR, Haseeb ASMA, Rubaiee S. Sustainability of additive-doped biodiesel: analysis of its aggressiveness toward metal corrosion. J Clean Prod. 2018;181:508-16.

58. Almeida ES, Portela FM, Sousa RMF, Daniel D, Terrones MGH, Richter E, et al. Behaviour of the antioxidant tertbutylhydroquinone on the storage stability and corrosive character of biodiesel. Fuel. 2011;90:3480-4. 